\title{
A measure of informed choice
}

\author{
Theresa M. Marteau PhD, Elizabeth Dormandy MSc and Susan Michie DPhil
}

Psychology and Genetics Research Group, Guy’s, King’s and St Thomas's School of Medicine, King's College, London, UK

Correspondence

Theresa M. Marteau

Psychology and Genetics

Research Group

Guy's, King's and

St Thomas's School of Medicine

King's College London

Guy's Campus London SE1 9RT

E-mail: theresa.marteau@kcl.ac.uk

Accepted for publication

24 January 2001

Keywords: informed choice, informed decision-making, measure, screening

\begin{abstract}
Objective To develop a measure of informed choice.

Conceptualization and measurement The measure is based on the following definition of an informed choice: one that is based on relevant knowledge, consistent with the decision-maker's values and behaviourally implemented. The measure comprises an eight-item scale of knowledge, a four-item scale assessing attitudes towards undergoing the screening test and a record of test uptake.
\end{abstract}

Participants Sixty-six women awaiting their first antenatal clinic appointments.

Measure development In women offered a screening test in pregnancy, the internal reliability of both the knowledge and the attitude scales was acceptable (alpha coefficients 0.82 and 0.83 , respectively). Of the 42 women completing both scales, 18 were classified as having made an informed choice, and 24 were classified as having made an uninformed choice.

Conclusion The results of this preliminary study provide some evidence to support the feasibility of conceptualizing and measuring informed choices regarding screening using a brief measure assessing knowledge and attitudes. The validity and utility of this approach awaits further studies, involving larger numbers of participants, offered different screening tests.

\section{The importance of informed choice}

Health policy in the UK emphasizes the importance of patient informed choice with regard to all treatments. The Patients' Charter, for example, states that patients have a right to be given a clear explanation of any treatment proposed, including any risks and alternatives, before they decide whether to agree to the treatment. ${ }^{1}$ The National Screening Committee for the UK is adopting a similar view regarding the rights of all those invited to participate in screening programmes. Hitherto, screening has largely been viewed as a public health activity aimed at reducing disease prevalence. In achieving this, the emphasis has been upon high rates of uptake, and not upon informed choice. ${ }^{2}$

The shift in emphasis towards informed choice reflects several considerations. First, it reflects an increasing recognition that it is unethical for individuals not to be informed of the consequences of medical interventions. Second, it reflects a belief that an informed choice, compared with an uninformed one, is associated with better patient outcomes. Few studies have examined the psychological or health consequences of informed choice in screening. In other areas of health-care, however, there is good 
evidence showing that psychological preparation for stressful medical procedures is associated with better psychological and clinical outcomes. ${ }^{3}$ How much benefit informed choice confers in screening programmes remains to be determined. A third factor that has contributed towards the emphasis upon informed choice is a concern that failure to appreciate the consequences of screening may result in litigation. ${ }^{4,5}$

\section{Definitions}

Many different terms are used, often interchangeably, to encompass informed choice. These include informed or effective decisions, and evidence-based choices, as illustrated below:

- An informed decision is one where all the available information about the health alternatives is weighed up and used to inform the final decision; the resulting choice should be consistent with the individual's values. ${ }^{6}$

- An evidence-informed patient choice is one in which individuals are given research-based information on two or more options and have some input into the decision-making process. ${ }^{7}$

- An effective decision is one that is informed, consistent with the decision-maker's values and behaviourally implemented. ${ }^{8}$

There is an emerging consensus that an informed choice or decision has two core characteristics: first, it is based on relevant, good quality information, and second, the resulting choice reflects the decision-maker's values.

\section{Measurement}

Many studies designed to assess informed choice do not attempt to measure the concept. In a systematic review of informed decision-making, Bekker and co-workers ${ }^{9}$ found that fewer than a third of 547 articles included a measure of the decision-making process. In these studies, the measures did not reflect the multidimensional nature of informed choice inherent in the definitions of the term. In a review of measures assessing the involvement of patients in shared decision-making, ${ }^{10}$ only one measure of infor- med decision-making was found. ${ }^{11}$ This, however, is based just upon a content analysis of information provided during consultations requiring no assessments from patients. Existing measures often use single items or multiple items assessing just a single dimension ${ }^{12,13}$ with the measurement presented in the form of mean scores. Single item measures of higher construct variables are unreliable, ${ }^{14}$ while single dimension measures (such as a measure of knowledge) are unable to reflect the multidimensionality of the construct of informed choice. Most often, only knowledge is assessed. Rarely are values assessed and, to our knowledge, there has been no attempt to produce a measure reflecting both knowledge and values.

Studies of informed choice should assess knowledge and values before a decision is made. This is to prevent the outcome of the decision colouring an individual's view of the choice they made. The nearer in time to a decision that measures are taken, the more valid the measure of the extent to which the choice was informed.

\section{Measuring informed choice in relation to screening}

The definition of informed choice that we are using is adapted from O'Connor and O'BrienPallas's definition of an effective decision: ${ }^{8}$

'An informed choice is one that is based on relevant knowledge, consistent with the decisionmaker's values and behaviourally implemented.'

Using this definition, an informed choice to undergo a screening test occurs when an individual has a positive attitude towards undergoing a test, has relevant knowledge about the test and undergoes it. An informed choice to decline a test occurs when an individual holds a negative attitude towards undergoing a test, has relevant knowledge about the test and does not undergo it. The choices that occur when individuals do not have relevant knowledge or when their attitudes are not reflected in their behaviour, are uninformed, using our classification system.

Uninformed choices may be the result of the influence of health professionals or the influence 
of practical barriers preventing individuals from realizing their intentions. For example, health professionals who present tests in a very positive or negative light may influence the decisions of those offered tests. Uptake of screening tests varies between health professionals, with those offered tests by health professionals with more positive attitudes being more likely to undergo the test than those offered by health professionals with less positive attitudes. ${ }^{12}$ Health professionals may also influence uptake by affecting knowledge. For example, health professionals who lack knowledge themselves will be unable to inform patients. ${ }^{15,16}$ Uptake of screening also varies according to how the test is offered. When offered as part of a routine visit, as opposed to requiring a separate visit, uptake is higher. ${ }^{6,17}$ There is some evidence to suggest that uptake following the offer of a test as part of a routine visit is based on poorer knowledge than when it requires a separate visit. ${ }^{18}$

Attitudes towards performing a behaviour, influence from others, and perceived barriers to the behaviour, are the three key components of a well-validated model of health behaviour, the theory of planned behaviour. ${ }^{19}$ This model provides a theoretical basis to our conceptualization of informed choice, in this case, undergoing screening. It also provides theory-based measures of these core constructs to form the basis for developing a measure of informed choice.

Using this approach, those offered a screening test can be classified into one of eight categories according to their knowledge (good vs poor), attitude towards the test (positive vs negative) and uptake (undergoes vs does not undergo the test) (Fig. 1). Cells 1 and 4 are those that represent the most informed choices: good knowledge, and uptake consistent with attitudes (i.e. the individual has a positive attitude towards the test and undergoes it as in cell 1; or, the individual has a negative attitude towards the test and does not undergo it as in cell 4). The remaining six cells represent a variety of ways in which choices are less informed. One of the cells, cell 6, would be seen as particularly problematic because tests are undergone by poorly informed individuals

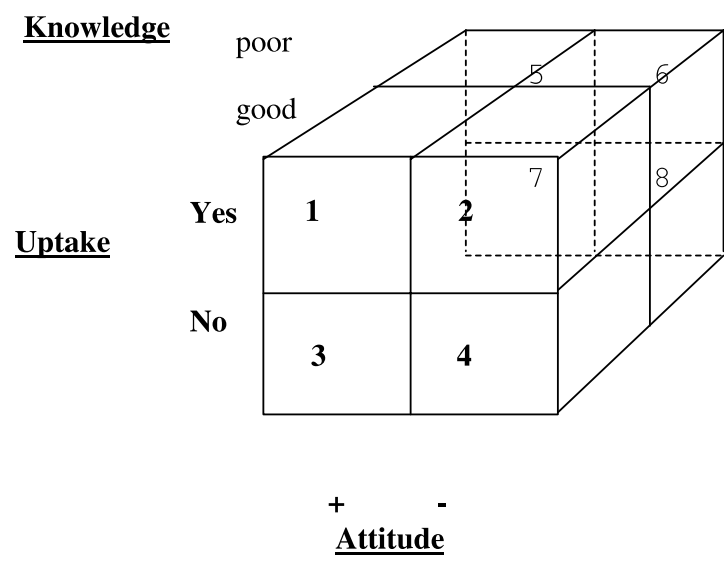

Figure 1 Classifying choices, based on the three dimensions of knowledge (good, poor), attitudes (positive, negative) and uptake (yes, no).

who, if better informed, would decline them. Reducing the number in cell 6 might be achieved by raising the barriers to undergoing the test. By contrast, a significant proportion in cell 3 would also be of concern, because those who are informed with positive attitudes are failing to undergo testing. The numbers in this cell might be reduced by removing possible practical barriers to undergoing the test. The extent to which each of these six cells results in adverse outcomes remains to be determined.

This typology allows services to be compared for rates and types of informed and uninformed choices that they achieve. It thus provides an outcome indicator for services such as screening programmes which aim to achieve informed choices. It also provides an indicator of which aspects of a service need to be altered to increase rates of informed choice.

Such a typology, however, begs some key questions, namely how are good and poor levels of knowledge, and positive and negative attitudes, to be quantified.

\section{Knowledge}

Some definitions of informed choice require that individuals appraise and use all available information. ${ }^{9}$ Individuals, however, vary in their need for and interest in information when facing a decision. ${ }^{20}$ While those running screening programmes need to be sensitive to this, their 
primary task is to provide the information sufficient for the great majority to make an informed choice.

There are several approaches to quantifying the information needed. One is to use professional guidelines, such as those produced by the General Medical Council (GMC). ${ }^{21}$ These state that, in order to ensure that screening is not contrary to the individual's interests, it is necessary to explain five points: the purpose of screening; the likelihood of positive and negative findings, alongside the possibility of false positive and false negative findings; the uncertainties and risks attached to the screening process; any significant medical, social or financial implications of screening; and follow-up plans, including the availability of counselling and support services. It should be noted, however, that these guidelines are not based on direct evidence, representing instead a professional consensus based on the available, indirect evidence.

A second approach is to seek the views of those who have been offered screening. Such a group comprises those who declined screening who subsequently developed the screened condition, as well as those who underwent screening and received one of four possible outcomes: true negative result; true positive result; false positive result; and false negative result. It is very likely that individuals with different outcomes of screening will recommend the provision of differing amounts and types of information. This raises the question of how the needs of the majority undergoing screening (i.e. those receiving true negative test results) should be pitted against those of a minority (i.e. those with other than true negative test results). One approach to resolving this is to use conjoint analysis $^{22}$ to compare the values that each of these different groups attach to the provision of information that will meet the needs of different groups undergoing screening.

A third approach to determining the information needed for an informed choice is a consequentialist one, in which the psychological outcomes of screening amongst those with differing types and amounts of knowledge are determined. Relevant psychological outcomes include satisfaction with information, anxiety and decision-regret. The knowledge associated with best outcomes can then be defined as good knowledge. It seems most probable that outcomes are predicted not by an informed choice per se, but by an interaction between informed choice and health outcome. Thus, the beneficial effects of making an informed choice are likely to be more marked in those with a problematic health outcome than in those with a good health outcome.

Using all three approaches is likely to provide the most valid estimate of the information needed for an informed choice.

\section{Attitudes}

Our definition of an informed choice requires assessment of an individual's values. A value can be defined as a basic attitude towards broad modes of conduct (e.g. courage, honesty and friendship) or certain end-states of existence (e.g. equality, freedom salvation, selffulfilment). ${ }^{23}$ Attitudes thus reflect values. Measurement of one specific attitude towards a screening test will encompass one or more salient values. We have therefore opted to assess specific attitudes rather than values, thereby minimizing the number of measures required. While there are many definitions of attitudes, the simplest one states that an attitude towards any concept is a person's general feeling of 'favourableness' or 'unfavourableness' for that concept. ${ }^{24}$ Thus, with regard to a screening test, the attitude of relevance is not the attitude towards the test per se, but rather the attitude towards undergoing the test. Thus, an individual may have a negative attitude towards a test (believing it for example to be painful or embarrassing) but a positive attitude towards undergoing it (e.g. fearing the consequences of not having the test). In relation to screening for Down's syndrome, a woman may have a negative attitude towards the test based on a negative attitude towards termination of pregnancies affected by Down's syndrome, but a positive attitude towards undergoing the test, 
if she believes, for example, that she would not have the resources to care for an affected child.

Conceptually it may be possible to make a distinction between attitudes towards undergoing a test and attitudes towards not undergoing it. Empirically, however, there is little evidence to support the value of measuring both such attitudes. ${ }^{25}$ In assessing attitudes towards undergoing a screening test, several items need to be used in order to attain sufficient reliability. Responses to these items can then be summed to classify individuals as having positive or negative attitudes.

\section{Development of the measure: the example of informed choice to undergo prenatal screening}

We report here the development of a measure designed to assess informed choice to undergo one particular screening test, prenatal screening for Down's syndrome. We envisage using the same approach to develop measures of informed choice to undergo other types of screening test. Results from a preliminary study designed to develop this measure are presented below.

\section{Sample and methods}

The sample comprised women awaiting their first antenatal appointments in a London hospital, when they were around 12 weeks pregnant. Half the women were approached again at around 20 weeks of pregnancy.

Sixty-six women completed the questionnaire regarding measures of knowledge and attitudes at 12 weeks pregnancy, when offered the screening test. Due to missing data on some items, totals do not always add up to 66. Thirtythree of these women were interviewed at 20 weeks pregnancy to validate the knowledge and attitude scales. This was after the time at which they could have undergone the test, but before they received their test results, all of which were negative or low risk.

\section{Knowledge}

The knowledge scale was developed using the first approach outlined above, i.e. the items were selected to reflect the information stated in professional guidelines to be essential for the exercise of an informed choice in relation to a screening test. ${ }^{21}$ These overlapped with items used in previous measures we have developed. ${ }^{16,26}$ The importance of these dimensions was reinforced by two focus groups we conducted with recently pregnant women. The scale is shown in Appendix 1. This was piloted with pregnant women and found to be comprehensible. The mean score obtained in the study sample of 66 pregnant women was 4.5 (SD 2.5, range $=0-8$ ). The median of four was taken to classify women's knowledge as good or poor, with scores above four indicating good knowledge, and those at four and below indicating poor knowledge. The terms good and poor imply an absolute standard against which knowledge is judged. It is intended that such a standard is developed in the future. For the present, however, the only standard is a relative one, that is, knowledge is judged as poor within the context of this sample.

\section{Internal reliability}

The alpha coefficient was 0.82 , which suggests that the scale is internally reliable.

\section{Construct validity}

This was assessed by comparing women's scores on the knowledge scale with their responses to open-ended questions designed to elicit their understanding of the test. Responses to these open-ended questions were coded by three raters as indicating good or poor knowledge (see Box 1). The mean score on the knowledge scale of the 20 women judged to have good knowledge was 5.8 (SD 1.8); the mean score of the 13 judged to have poor knowledge was 4.4 (SD 1.5) $(t(1,31)=2.4 ; P=0.023)$.

\section{Attitudes}

This comprises four items based upon measures taken from the Theory of Planned Behaviour. ${ }^{27}$ 
Box 1 Responses of women to open-ended questions eliciting knowledge about the test and attitudes towards undergoing the test

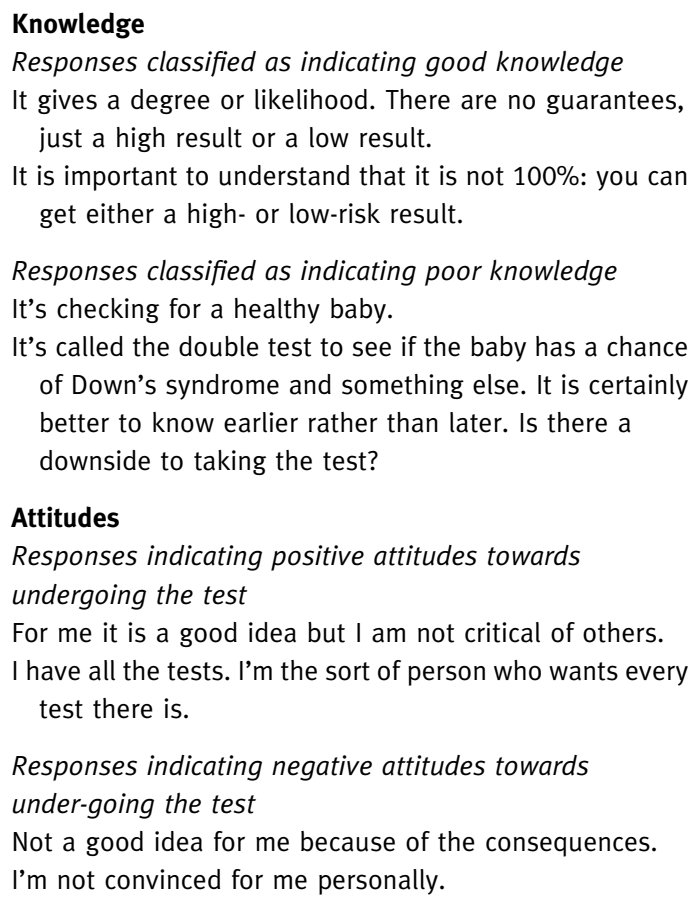

Responses indicating negative attitudes towards under-going the test

Not a good idea for me because of the consequences. I'm not convinced for me personally.

The scale is shown in Appendix 1. Responses to the scale are used to classify women as having a positive or a negative attitude towards undergoing or declining prenatal screening. The overall score for the sample of 49 of the 66 women who completed the scale was 20.8 $(\mathrm{SD}=5.5$, range $=4-28)$. The median of 22 was taken to classify women's attitudes as positive or negative, with scores 22 or above indicating positive attitudes, and those below 22 indicating negative attitudes. As for knowledge, the terms positive and negative imply an absolute standard against which attitudes are judged. It is intended that such a standard is developed in the future. For the present, however, the only standard is a relative one, that is, attitudes are judged as negative within the context of this sample.

\section{Internal reliability}

The alpha coefficient of reliability is 0.83 , indicating good internal reliability of the scale.

\section{Construct validity}

This was assessed by comparing women's scores on the attitude scale with their responses to open-ended questions designed to elicit their attitudes towards the test. Responses to these open-ended questions were coded by three raters as indicating a positive or a negative attitude (see Box 1). The mean score on the attitude scale of the 18 women judged to have positive attitudes was 22.6 (SD 4.0); the mean score of the 11 judged to have negative attitudes was 16.2 (SD 6.0) $(t(27)=3.4 ; P=0.002)$.

\section{Uptake}

This was determined from laboratory records. There was $100 \%$ agreement between these and women's reports of whether or not they had undergone the screening test.

\begin{tabular}{lllll}
\hline & $\begin{array}{l}\text { Good } \\
\text { knowledge }\end{array}$ & $\begin{array}{l}\text { Positive } \\
\text { attitudes }\end{array}$ & Uptake & $\begin{array}{l}\text { Number of } \\
\text { women }\end{array}$ \\
\hline Informed choices & & & & \\
Cell 1 = informed choice & $\checkmark$ & $\checkmark$ & $\checkmark$ & 14 \\
Cell 4 = informed choice & $\checkmark$ & $\times$ & $\times$ & 4 \\
Uninformed choices & & & & \\
Cell 2 = uninformed choice & $\checkmark$ & $\times$ & $\checkmark$ & 7 \\
Cell 3 = uninformed choice & $\checkmark$ & $\checkmark$ & $\times$ & 2 \\
Cell 5 = uninformed choice & $\times$ & $\checkmark$ & $\checkmark$ & 7 \\
Cell 6 = uninformed choice & $\times$ & $\times$ & $\checkmark$ & 4 \\
Cell 7 = uninformed choice & $\times$ & $\checkmark$ & $\times$ & 2 \\
Cell 8 = uninformed choice & $\times$ & $\times$ & $\times$ & 2 \\
\hline
\end{tabular}

Table 1 Distribution of choices for 42 women, across the eight-cell typology shown in Fig. 1 


\section{Classification of choices as informed} and uninformed

The responses of 42 women who had completed both the knowledge and attitude scales were used to classify choices as informed or uninformed. Their choices were classified into one of the eight types depicted in Fig. 1. Eighteen decisions were classified as informed and 24 as various types of uninformed choices (Table 1).

Fourteen of the informed choices were those in which women with good knowledge and positive attitudes had undergone the test (cell 1). The remaining four informed choices were those in which women with good knowledge and negative attitudes had not undergone the test (cell 4). Fifteen of the 24 uninformed choices reflected poor knowledge (cells 5, 6, 7, 8); 15 also reflected behaviour that was inconsistent with attitudes, i.e. undergoing the test while having a negative attitude towards it $(n=11)$ (cells 2 and 6 ), or not having the test despite a positive attitude towards it $(n=4)$ (cells 3 and 7).

\section{Discussion}

The results of this preliminary study provide evidence to support the feasibility of conceptualizing and measuring informed choices regarding screening using a brief measure assessing knowledge, attitudes and behaviour. By taking account of variation along these three dimensions in ascertaining whether a choice is informed or not, this measure advances previous attempts at operationalisation of this concept. To our knowledge these have not gone beyond one dimension, as discussed in the introduction to this paper. The validity and utility of this approach await further studies, involving larger numbers of participants, offered different screening tests.

The definition and hence the measure we presented are based on a categorical conceptualization of informed choice. There are strengths as well as weaknesses with such an approach. In terms of strengths it produces a very simple way of determining whether or not a decision is informed. The typology also provides informa- tion on the ways in which decisions are not informed and hence the types of interventions needed to increase rates of informed choice. The weakness of using a categorical classification is that it ignores some of the variance in responses, thus reducing its sensitivity. Whether it is sufficiently sensitive for use as an outcome measure of a screening programme remains to be determined. The current data provide equivocal evidence for using binary classification of knowledge and attitudes. While there was good evidence that attitudes were bimodally distributed in the current sample, knowledge was more normally distributed, raising questions about the validity of using median splits to classify individuals. Given the small sample size, the validity of our proposed typology remains to be determined in larger data sets.

Further developments of the measure include refinements to the knowledge scale based upon data from those with different outcomes of screening, and the views of health professionals with screening experience. While our measure incorporates a generic attitude measure, the measure of knowledge needs to be specified for each screening test. A generic measure of knowledge would make application of the informed choice measure far simpler. Such a measure would comprise a self-report of knowledge, as opposed to a knowledge test. Research in other areas, however, casts doubt on such a goal, showing that the association between what people know and their estimates of this knowledge is positive but not perfect, with people tending to overestimate how much they know. $^{28,29}$ It may, however, be possible to generate a template of information about any screening test that is a prerequisite to informed choice. Moving beyond simple measurement of knowledge and attitudes, research is needed to assess the dynamic nature of the relationship between knowledge and attitudes and the implications of this for a measure of informed choice. Do, for example, attitudes towards a test influence how much information is sought or retained about the test? Does having certain pieces of information about a test predict attitudes? 
Given the plans for a large expansion in screening programmes in the $\mathrm{UK},{ }^{30}$ it becomes increasingly urgent to be able to assess the extent to which choices to undergo or to decline screening are informed. The definition and measure presented in this paper represent the first steps towards addressing this need.

\section{Acknowledgements}

This research is funded by The Wellcome Trust. This paper was presented at a workshop on informed choice organised by the National Screening Committee. We are grateful for comments to an earlier draft of this paper from those attending the meeting.

\section{References}

1 Department of Health. The Patient's Charter. London: Her Majesty's Stationary Office, 1991.

2 Raffle AE. Cervical cytology screening 10 years on. Trends in Urology, Gynaecology and Sexual Health, 1998; 3: 14-16.

3 Johnston M, Vogele C. Benefits of psychological preparation for surgery: a meta-analysis. Annals of Behavioural Medicine, 1993; 15: 245-256.

4 Petticrew MP, Sowden AJ, Lister-Sharp D, Wright K. Health Technology Assessment, 2000; 4 (5).

5 Wilson RM. Screening for breast and cervical cancer as a common cause for litigation. British Medical Journal, 2000; 320: 1352-1353.

6 Bekker H, Modell M, Dennis G et al. Uptake of cystic fibrosis carrier testing in primary care: supply push or demand pull? British Medical Journal, 1993; 306: 1584-1586.

7 Entwistle VA, Sheldon TA, Sowden A, Watt IS. Evidence-informed patient choice: practical issues of involving patients in decisions about health-care technologies. International Journal of Technological Assessment in Health-care, 1998; 14: 212-225.

8 O'Connor A, O'Brien-Pallas LL. Decisional conflict. In Mcfarlane GK, Mcfarlane EA (eds) Nursing Diagnosis and Intervention. Toronto: Mosby, 1989: 486-496.

9 Bekker H, Thornton J, Airey M et al. Informed decision-making: an annotated bibliography and systematic review. Health Technology Assessment, 1999; 3 (1).

10 Elwyn G, Edwards A, Mowle S et al. Measuring the involvement of patients in shared decision-making: a systematic review of instruments. Patient Education and Counseling, 2000; 1406: 1-19.
11 Braddock CH 3rd, Fihn SD, Levinson W, Jonsen AR, Pearlman RA. How doctors and patients discuss routine clinical decisions. Informed decision naming in the outpatient setting. Journal of General Internal Medicine, 1997; 12: 399-345.

12 Simpson WM, Johnstone F, Boyd F et al. Uptake and acceptability of antenatal HIV testing: randomised controlled trial of different methods of offering the test. British Medical Journal, 1998; 316: 262-267.

13 Kirkham M, Stapleton. Informed Choice in Maternity Care: An evaluation of evidence-based leaflets. York NHS Centre for Reviews \& Dissemination, 2001; In press.

14 Turk DC, Kerns RD. Assessment in health psychology: a cognitive-behavioural perspective. In. Karoly P (ed.) Measurement Strategies in Health Psychology. New York: Wiley, 1985; 335-372.

15 Smith D, Shaw RW, Marteau T. Lack of knowledge in health professionals: a barrier to providing information to patients. Quality in Health Care, 1994; 3: 75-78.

16 Smith DK, Shaw RW, Marteau TM. Informed consent to undergo serum screening for Down syndrome: the gap between policy and practice. British Medical Journal, 1994; 309: 776.

17 Dormandy E, Michie S, Weinman J, Marteau TM. Variation in uptake of serum screening: the role of service delivery. Prenatal Diagnosis, In press.

18 Tambor ES, Berhardt BA, Chase GA et al. Offering cystic fibrosis carrier screening to an HMO population: factors associated with utilization. American Journal of Human Genetics, 1994; 55: 626-637.

19 Ajzen I. The theory of planned behavior. Organizational Behavior and Human Decision Processes, 1991; 50: 179-211.

20 Miller SM, Mangan CE. Interacting effects of information and coping style in adapting to gynecologic stress: should the doctor tell all? Journal of Personal and Social Psychology, 1983; 45: 223-236.

21 General Medical Council. Seeking Patients' Consent: the Ethical Considerations. London: GMC, 1999.

22 Ryan M. Using Consumer Preferences in HEALTHCARE DECISION-MAKING: The Application of Conjoint Analysis. Luton: Office of Health Economics, 1996.

23 Rokeach M. Beliefs, Attitudes and Values San Francisco: Jossey-Bass, 1968.

24 Ajzen I, Fishbein M. Understanding Attitudes and Predicting Social Behavior. Englewood Cliffs, New Jersey: Prentice Hall, 1980.

25 Fishbein M, Ajzen I. Belief, Attitude, Intention and Behavior. An Introduction to Theory and Research. Reading, Massachusetts: Addison-Wesley, 1975.

26 Marteau T, Johnston M, Plenicar M, Shaw RW, Slack J. Development of a self-administered questionnaire to measure women's knowledge of prenatal 
screening and diagnostic tests. Journal of Psychosomatic Research, 1988; 32: 403-408.

27 Conner M, Norman P eds. Predicting Health Behaviour. Buckingham: Open University Press, 1996.

28 Keren G. Calibration and probability judgements: conceptual and methodological issues. Acta Scandinavia, 1991; 77: 217-273.

29 Ferguson E, Cox T, Farnsworth W, Leiter M, Irving $\mathrm{K}$. A measure of medical and non-medical students' knowledge and confidence in knowledge of HIV and AIDS. reliability and validity. AIDS Care, 1995; 7: 211-228.

30 Department of Health. The NHS Plan: a Plan for Investment, A Plan for Reform. London: The Stationary Office, 2000.

\section{Appendix 1 Measures}

\section{A. Knowledge}

1. Which of these conditions do you think that the test screens for? (you may tick more than one box for this question)

Spina bifida

Anaemia

Down's syndrome

Most abnormalities

None of these

Don't know

2. If 100 women decided to have the screening test, about how many do you think would have a low-risk result?

100

None

50

95

5

Not sure

3. What do you think a low-risk result means?

The baby definitely does not have Down's syndrome

It is highly unlikely that the baby has Down's syndrome

The baby might have Down's syndrome

It is highly likely that the baby has Down's syndrome

The baby definitely does have Down's syndrome

None of these

Don't know
4. Again, imagine that 100 women undergo the test. About how many do you think would have a high-risk result?

100

None

50

95

5

Not sure

5. What do you think a high-risk result means? The baby definitely does not have Down's syndrome

It is highly unlikely that the baby has Down's syndrome

The baby might have Down's syndrome

It is highly likely that the baby has Down's syndrome

The baby definitely does have Down's syndrome

None of these

Don't know

6. Imagine 100 women with a high-risk result. About how many do you think will be found to have a baby with Down's syndrome?

100

50

25

2

Not sure

7. Some women are offered further tests (amniocentesis or CVS, which involve inserting a fine needle into the womb). What are the possible consequences of this test?

8. If the further tests show that the baby definitely does have Down's syndrome, what would a woman be offered:

Immediate treatment for the baby

Another type of test

A termination of pregnancy

Extra vitamins

None of these

Not sure

\section{B. Attitudes}

Your thoughts about the screening test:

For the following questions, please circle the number from 1 to 7 on the scale that best 
describes how you feel at the moment. For example in question 1(a) if you thought having the screening test would be very beneficial, you would circle 1. If you thought it was a slightly beneficial, you would circle 3 and if you thought it was a slightly harmful thing you would circle 5. Please read the scale for each question.
For me, having the screening test for Down's syndrome when I am 15 weeks pregnant will be:
(a) Beneficial 1234567 Harmful
(b) Important 1234567 Unimportant
(c) Bad thing 1234567 Good thing
(d) Pleasant 1234567 Unpleasant 